\title{
Pathologic complete response after esophagectomy following neoadjuvant chemoradiation therapy for esophageal carcinoma: A cure sometimes?
}

\author{
Shawn S. Groth, MD, MS, FACS \\ From the Division of Thoracic Surgery, Michael E. DeBakey Department of Surgery, Baylor College of Medicine, \\ Houston, Tex. \\ Disclosures: Author has nothing to disclose with regard to commercial support. \\ Received for publication Oct 8, 2018; accepted for publication Oct 9, 2018; available ahead of print Nov 14, 2018. \\ Address for reprints: Shawn S. Groth, MD, MS, FACS, Division of Thoracic Surgery, Michael E. DeBakey \\ Department of Surgery, One Baylor Plaza, BCM 390, Houston, TX 77030 (E-mail: Shawn.Groth@bcm.edu). \\ J Thorac Cardiovasc Surg 2019;157:1260-1 \\ $0022-5223 / \$ 36.00$ \\ Copyright (c) 2018 by The American Association for Thoracic Surgery \\ https://doi.org/10.1016/j.jtcvs.2018.10.041
}

A pathologic complete response after esophagectomy following neoadjuvant therapy for locally advanced esophageal carcinoma is not synonymous with a cure. Although a pathologic complete response is associated with improved overall and disease-free survival rates, about $20 \%$ to $40 \%$ of patients will have a recurrence, ${ }^{1-3}$ most within the first 2 years. $^{4}$ To paraphrase Hippocrates, although we often treat, we only sometimes cure.

In this edition of the Journal, Barbetta and colleagues ${ }^{1}$ report a single-institution retrospective review of 233 patients with stage II or III esophageal cancer who underwent esophagectomy after neoadjuvant chemoradiation therapy during a 10-year period and were found to have had a pathologic complete response. This is an important study, with relevance to the everyday clinical practice of esophageal surgeons. Although the recurrence and disease-free survival rates are similar to those in other studies, there are several unique, salient findings of this study worth discussing.

First, as shown by the Kaplan-Meier curves, risk is not constant - it changes throughout the course of follow-up. Indeed, although $26.2 \%$ of patients in this study had a recurrence, most $(73 \%)$ recurrences were within the first 2 years. Although simply hypothesis generating and neither the intent of the study nor supported by its data, perhaps patients with a pathologic complete response should undergo a more intensive surveillance program, such as crosssectional surveillance imaging every 3 months, for the first 2 years after esophagectomy. Further studies are needed to ascertain whether early detection of recurrence in such patients affects survival.

Second, few studies have examined risk factors for recurrence after a pathologic complete response. Barbetta and colleagues $^{5}$ found that poor tumor differentiation is independently associated with an increased risk of recurrence. Similar to other studies, most $(72 \%)$ of the recurrences were distant metastases, implicating a need for better

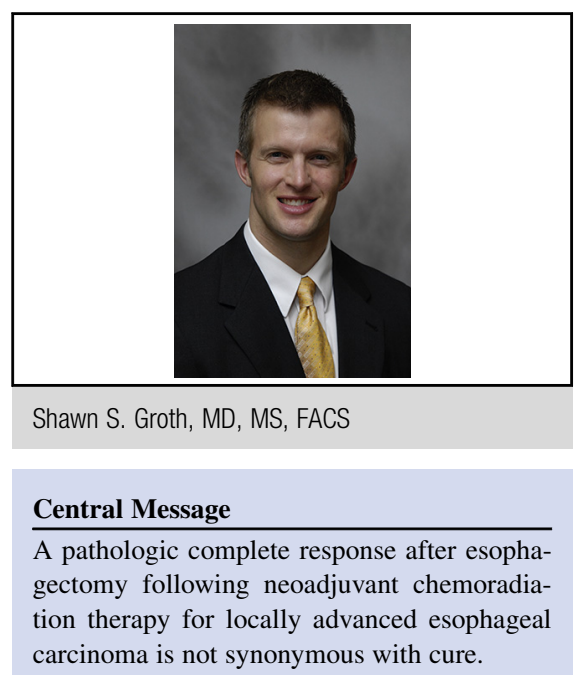

See Article page 1249 . systemic tumor control. The only cohort of patients proven to benefit from adjuvant chemotherapy after esophagectomy following neoadjuvant chemoradiation therapy are those patients with residual nodal disease. ${ }^{6}$ Perhaps consideration should also be given to placing patients with poorly differentiated tumors that had a pathologic complete response to neoadjuvant therapy on a course of standard systemic therapy or single-agent maintenance therapy after esophagectomy to mitigate this risk. A clinical trial to test this hypothesis is needed.

Finally, this and other recent studies have demonstrated a surprising number $(25 \%-30 \%)$ of patients with a pathologic complete response develop brain metastases. Although not currently included in National Comprehensive Cancer Network guidelines for posttreatment surveillance, this study suggests that routine cross-sectional brain imaging should be considered for patients with esophageal adenocarcinoma who have had a pathologic complete response.

Outcomes after esophagectomy have been "the tale of men repeatedly losing to a stronger adversary yet persisting in an unequal struggle until the nature of the problem became apparent and the war was won." 7 Indeed, despite numerous contemporaneous improvements in patient care, survival for patients with esophageal cancer has improved little during the past several decades. The knowledge that we gain from studies such as that of Barbetta and 
colleagues ${ }^{5}$ should help us to evolve our patient care strategies and make strides against this disease.

\section{References}

1. Oppedijk V, van der Gaast A, van Lanschot JJ, van Hagen P, van Os R, van Rij CM, et al. Patterns of recurrence after surgery alone versus preoperative chemoradiotherapy and surgery in the CROSS trials. J Clin Oncol. 2014;32:385-91.

2. Vallböhmer D, Hölscher AH, DeMeester S, DeMeester T, Salo J, Peters J, et al. A multicenter study of survival after neoadjuvant radiotherapy/chemotherapy and esophagectomy for ypT0N0M0R0 esophageal cancer. Ann Surg. 2010;252:744-9.

3. van Hagen P, Wijnhoven BP, Nafteux P, Moons J, Haustermans K, De Hertogh G, et al. Recurrence pattern in patients with a pathologically complete response after neoadjuvant chemoradiotherapy and surgery for oesophageal cancer. Br J Surg. 2013;100:267-73.
4. Xi M, Yang Y, Zhang L, Yang H, Merrell KW, Hallemeier CL, et al Multi-institutional analysis of recurrence and survival after neoadjuvant chemoradiotherapy of esophageal cancer: impact of histology on recurrence patterns and outcomes. Ann Surg. January 12, 2018 [Epub ahead of print].

5. Barbetta A, Sihag S, Nobel T, Hsu M, Tan K, Bains M, et al. Patterns and risk of recurrence in esophageal cancer patients with a pathological complete response after chemoradiotherapy followed by surgery. J Thorac Cardiovasc Surg. 2019; 157:1249-59.

6. Burt BM, Groth SS, Sada YH, Farjah F, Cornwell L, Sugarbaker DJ, et al. Utility of adjuvant chemotherapy after neoadjuvant chemoradiation and esophagectomy for esophageal cancer. Ann Surg. 2017;266:297-304.

7. Elmslie R. Perspectives in the development of oesophageal surgery. In Jamieson GG, ed. Surgery of the Oesophagus. London: Churchill Livingstone: 1988:3-8. 